Supplement of The Cryosphere, 12, 675-683, 2018 https://doi.org/10.5194/tc-12-675-2018-supplement (C) Author(s) 2018. This work is distributed under the Creative Commons Attribution 4.0 License.

(c) (i)

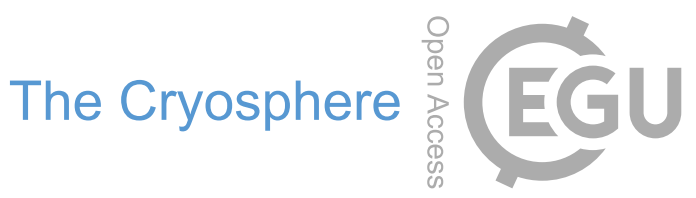

Supplement of

\title{
Mechanisms influencing seasonal to inter-annual prediction skill of sea ice extent in the Arctic Ocean in MIROC
}

Jun Ono et al.

Correspondence to: Jun Ono (jun.ono@ jamstec.go.jp)

The copyright of individual parts of the supplement might differ from the CC BY 4.0 License. 
(a) SIE.NH.ANOM Proid 1980-2009

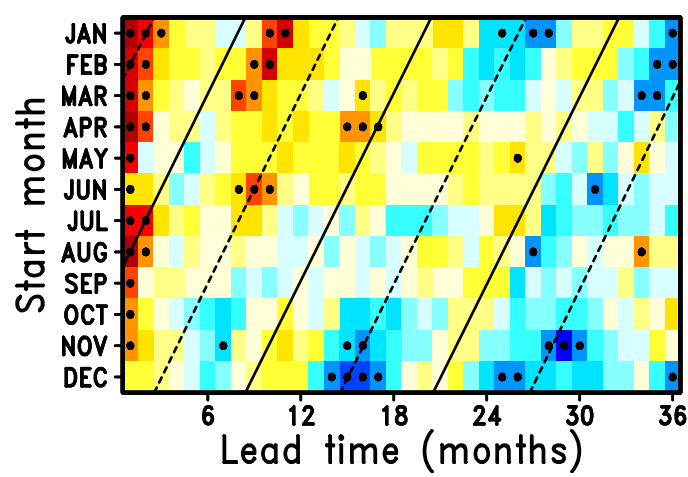

(c) SIE.NH ANOM NSIDC_1980-2009

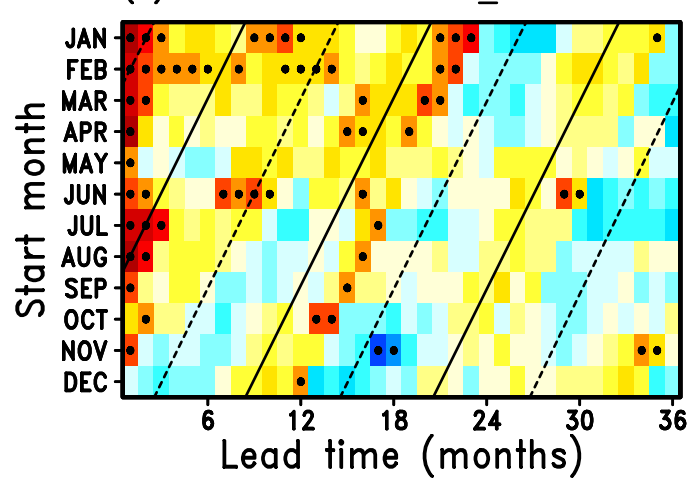

(e) SIE ${ }_{A 0}$ VS SIE.NH NSIDC 1980-2009

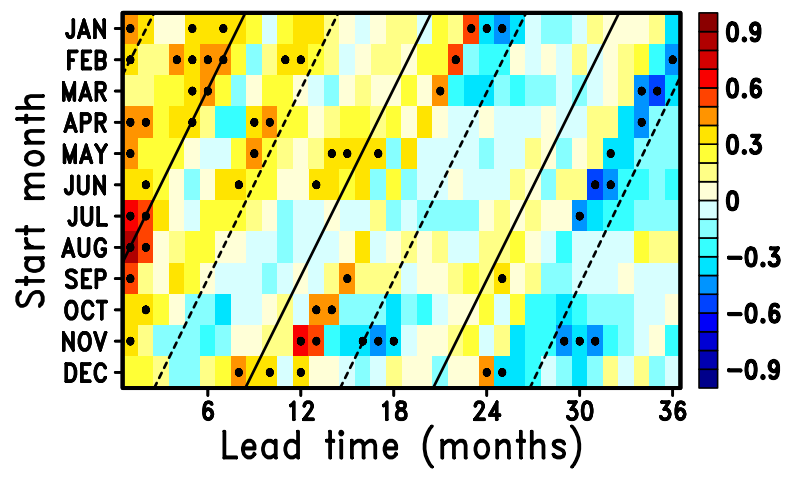

(b) SIE.NH.ANOM MIROC 1980-2009

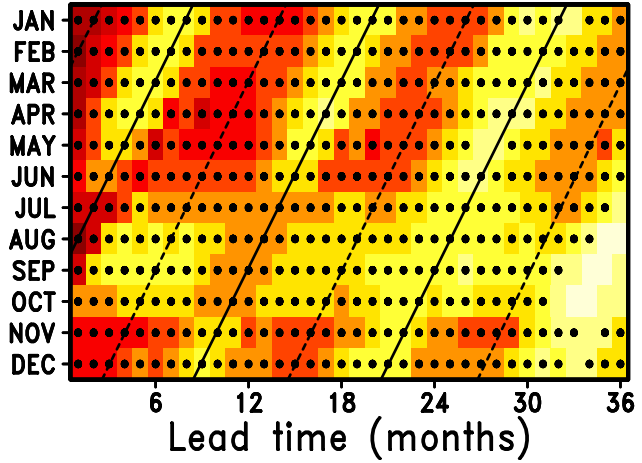

(d) SIE.NH NSIDC_1979-2012

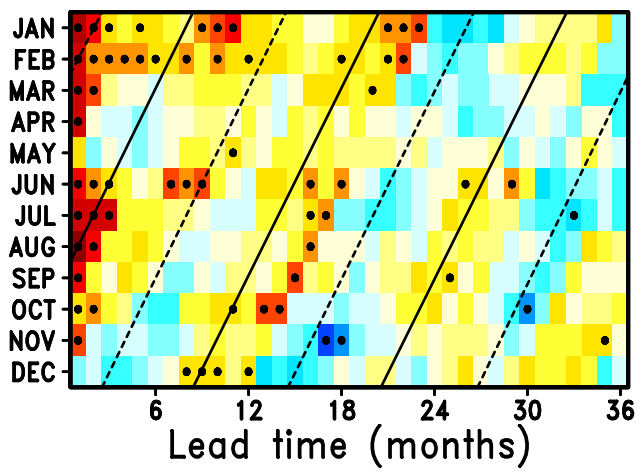

Figure S1. Lagged auto-correlation coefficients for the detrended sea ice extent anomaly in the Northern Hemisphere derived from (a) observations (Ishii et al., 2006; Ishii and Kimoto, 2009) and (b) a model control simulation, and (c) the National Snow and Ice Data Centre (NSIDC). In (d), the lagged correlations were calculated for the detrended sea ice extent from NSIDC during 1979-2012. In (e), lagged cross-correlation coefficients between the detrended $\mathrm{SIE}_{\mathrm{AO}}$ anomaly derived from observations (Ishii et al., 2006; Ishii and Kimoto, 2009) and the detrended sea ice extent anomaly in the Northern Hemisphere derived from NSIDC are also shown. Solid and dashed lines denote values for the September and March target months, respectively. Black dots indicate statistical significance at the $95 \%$ confidence level based on a two-sided Student's t-test with 30 (34 for (d)) and 200 degrees of freedom in the observations and model, respectively. 

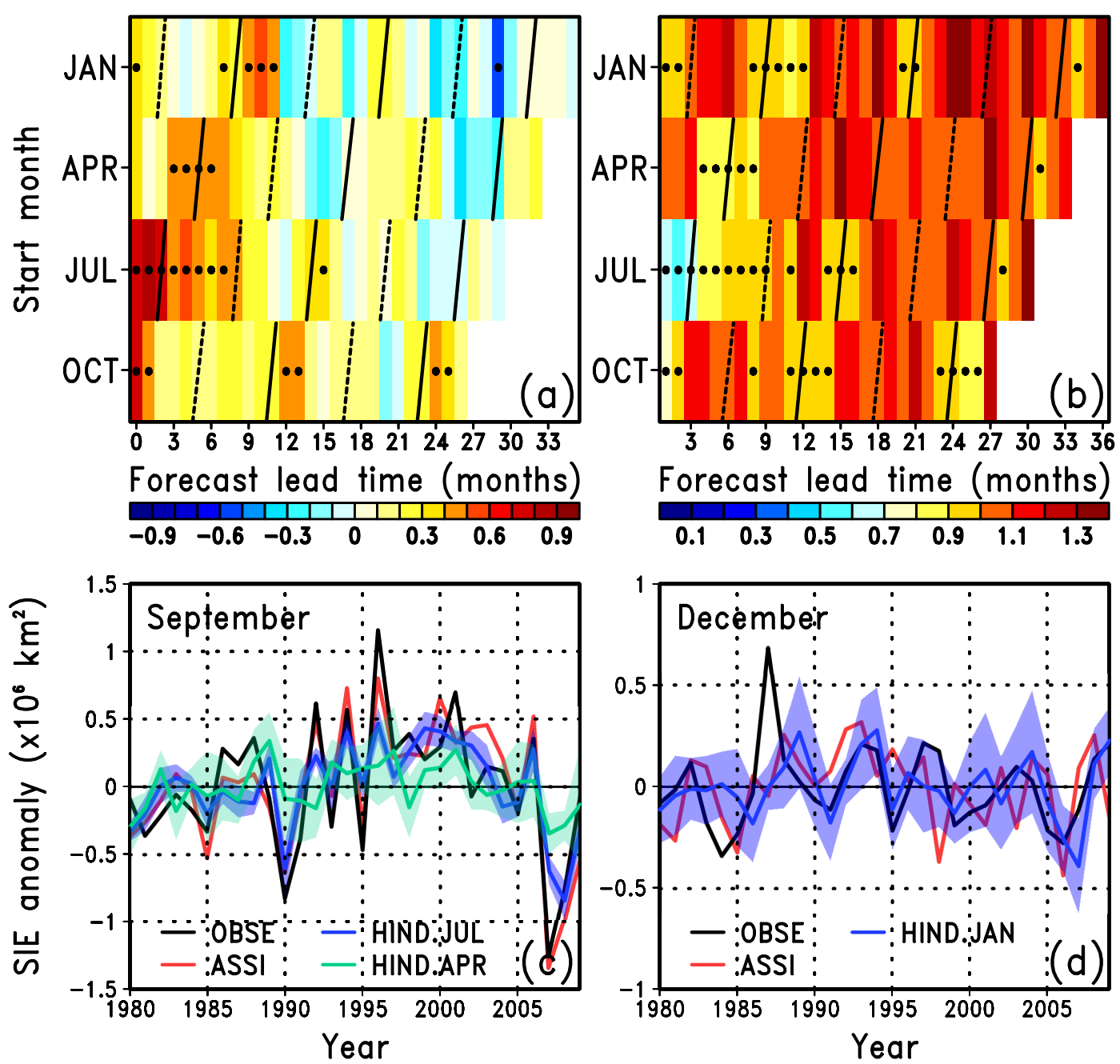

Figure S2. As in Fig. 2, except that the detrended sea ice extent anomaly is calculated for the Northern Hemisphere. 


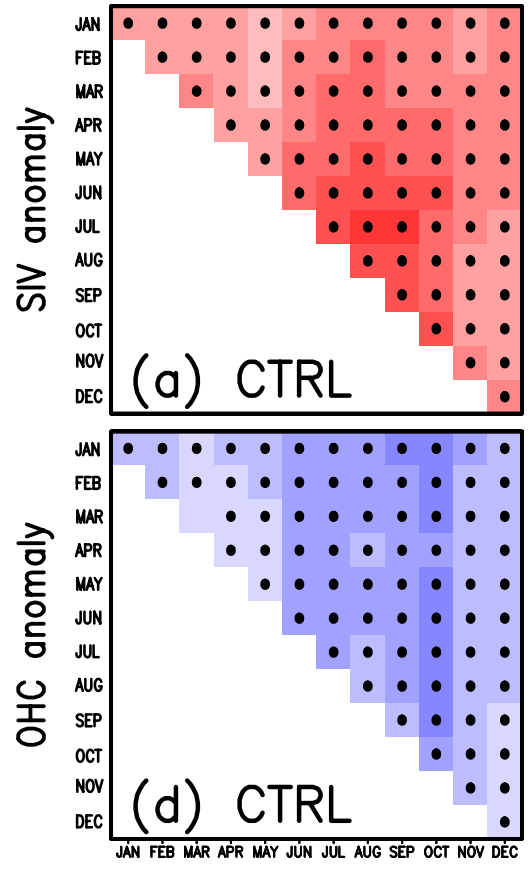

SIE anomaly
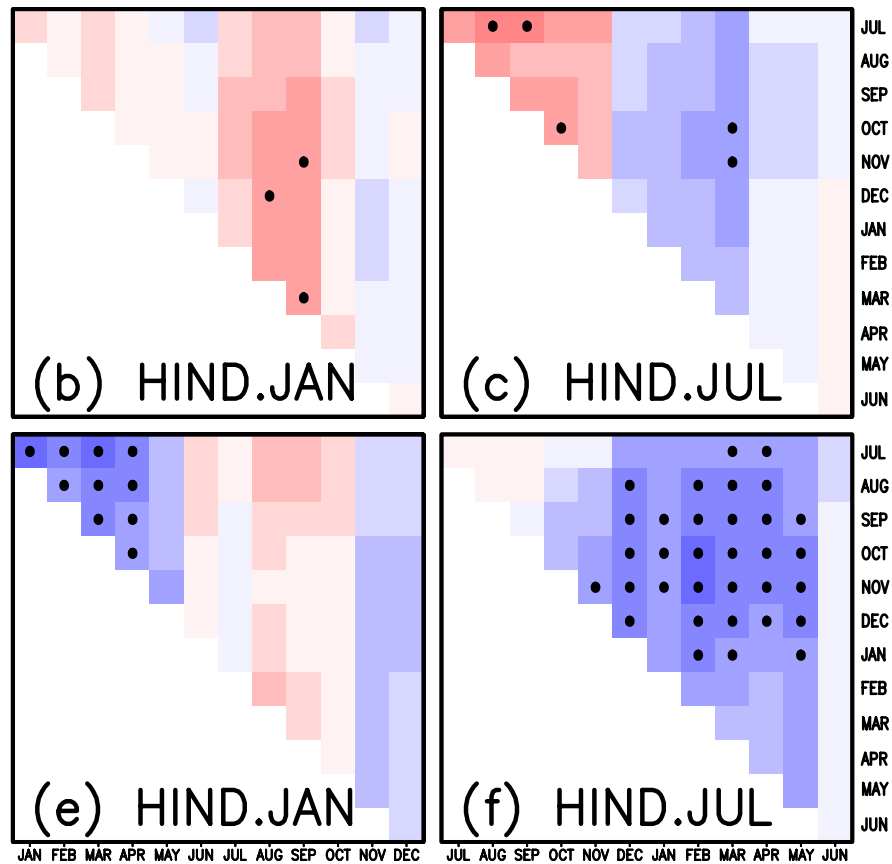

SIE anomaly

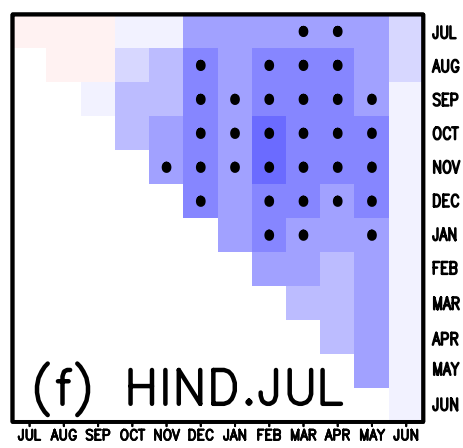

SIE anomaly

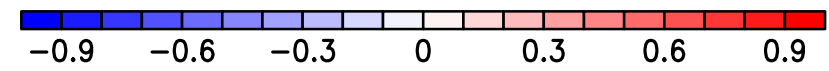

Figure S3. As in Fig. 3, except that the SIE, SIV, and OHC anomalies are calculated for the Northern Hemisphere. 


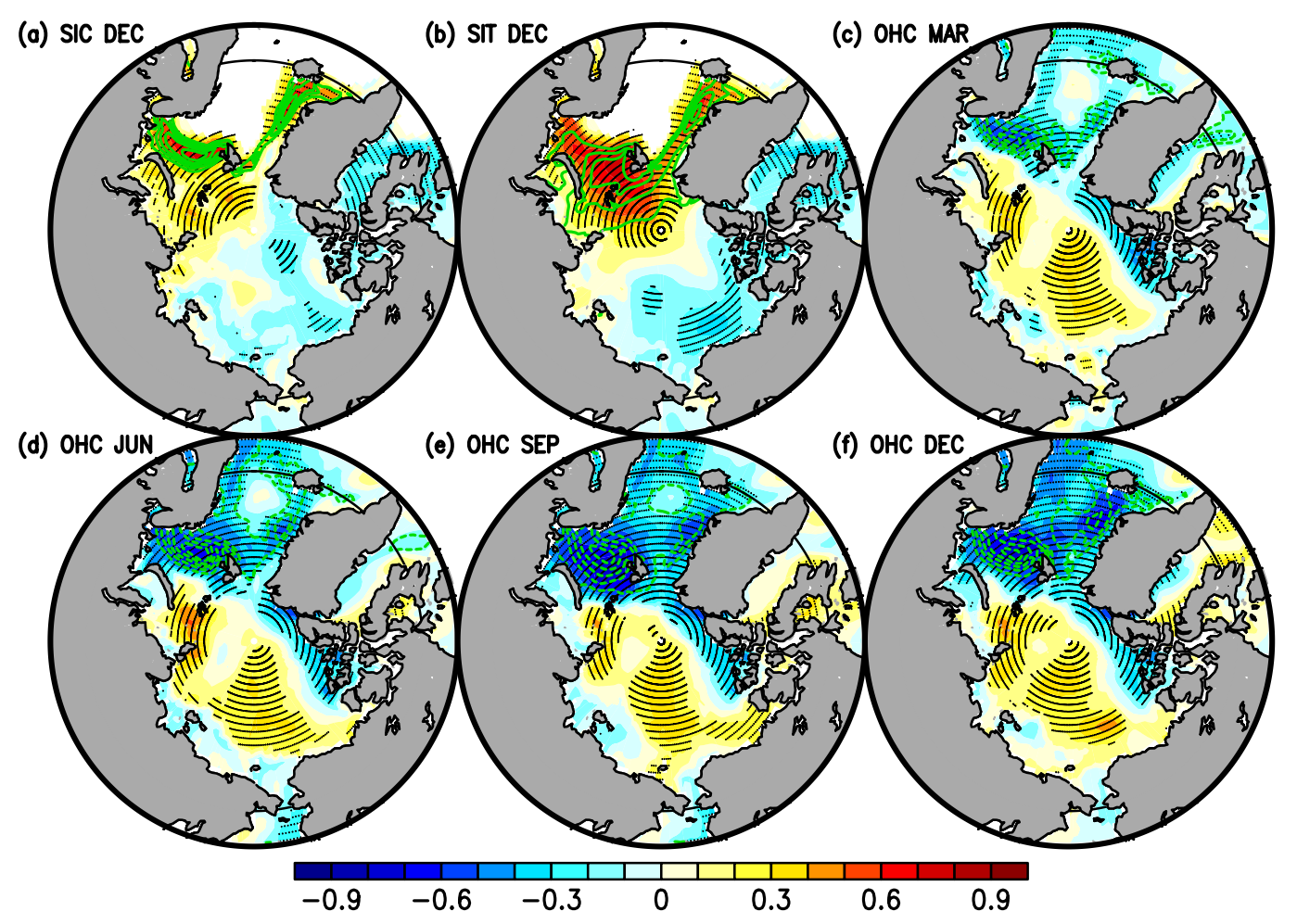

Figure S4. As in Fig. 4, except for the control experiment. 


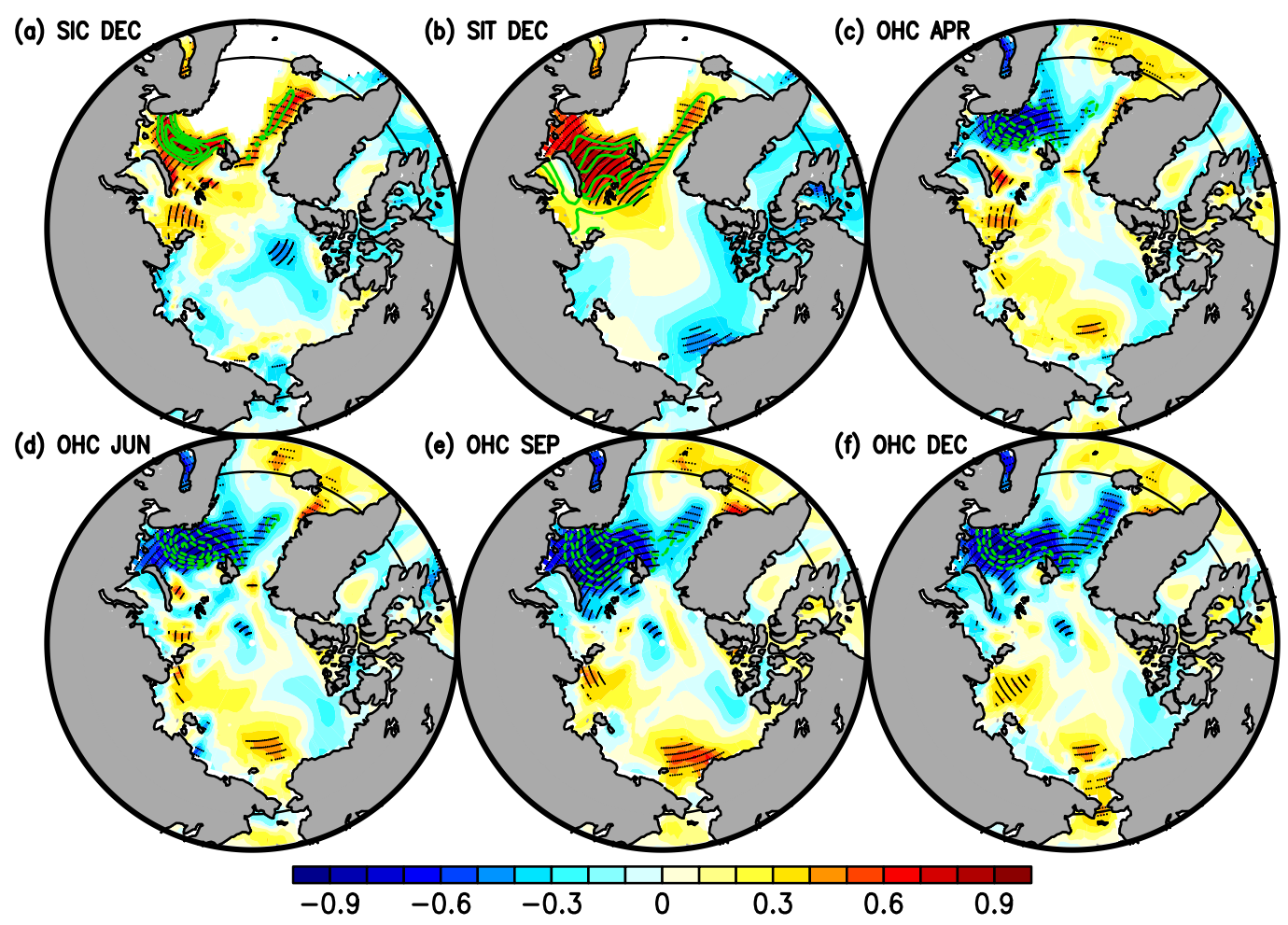

Figure S5. As in Fig. 4, except for the hindcasts started from April 1st. Lagged correlation and regression coefficients in (c) are at lag -8 months (APR). 

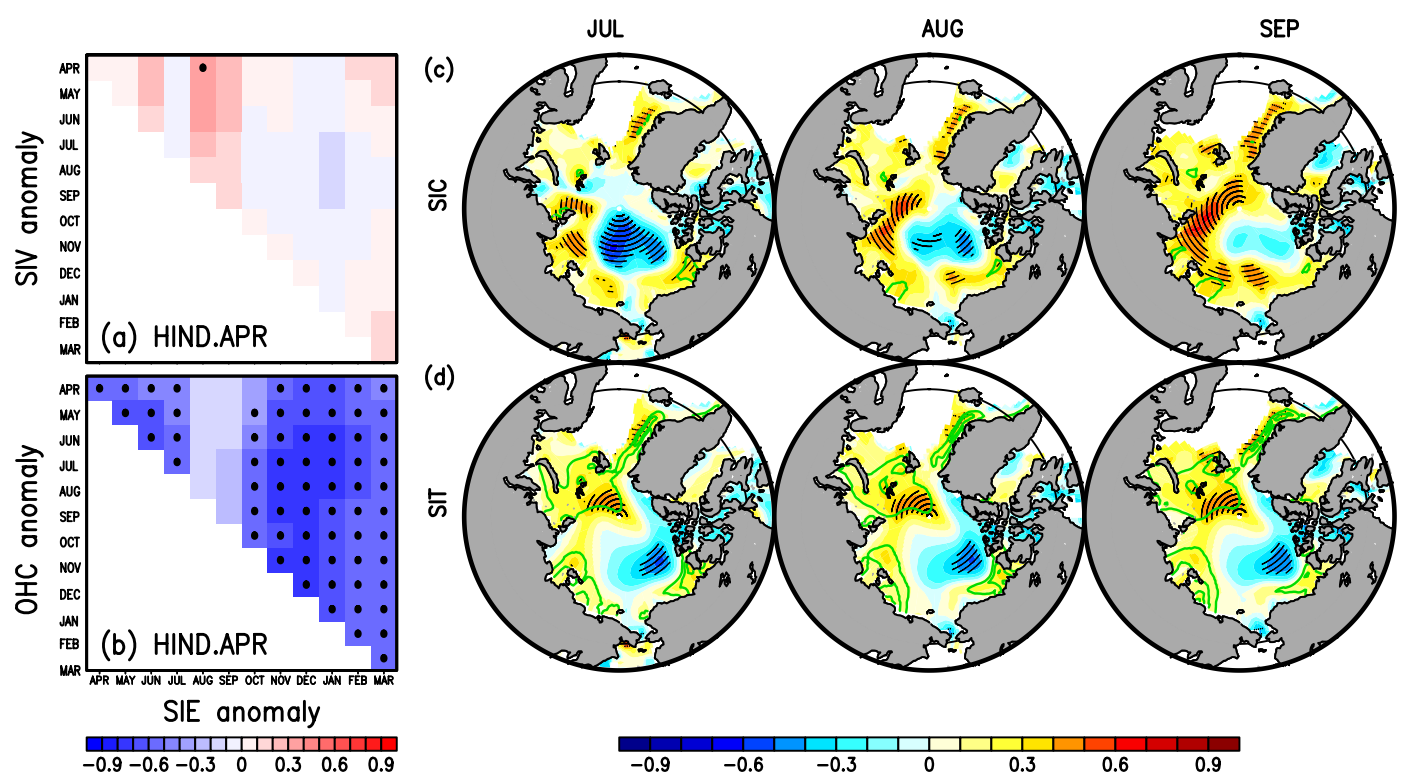

Figure S6. Lagged correlation coefficients between the detrended $\mathrm{SIE}_{\mathrm{AO}}$ anomaly and (a) the detrended $\mathrm{SIV}_{\mathrm{AO}}$ anomaly and (b) the detrended $\mathrm{OHC}_{\mathrm{AO}}$ anomaly from the hindcasts started from April 1st (HIND.APR). Black dots indicate statistical significance at the $95 \%$ confidence level based on a two-sided Student's t-test with 30 degrees of freedom. Lagged correlation (colors) and regression (contours) coefficients between September SIE $\mathrm{AO}$ anomaly $\left(\times 10^{6} \mathrm{~km}^{2}\right)$ and (c) SIC anomaly (\%) and (d) SIT anomaly (cm) at lag -2 (JUL), -1 (AUG), and 0 (SEP) months, in regions from $60^{\circ}$ to $90^{\circ} \mathrm{N}$, based on the hindcasts started from April 1st. Contour intervals are $5(\%)$ for SIC and $5(\mathrm{~cm})$ for SIT. Stippling indicates regions with statistically significant correlation coefficients at the $95 \%$ confidence level. White shading indicates areas where sea ice does not exist. A latitude circle of $65^{\circ} \mathrm{N}$ is also indicated by a thin solid line. 


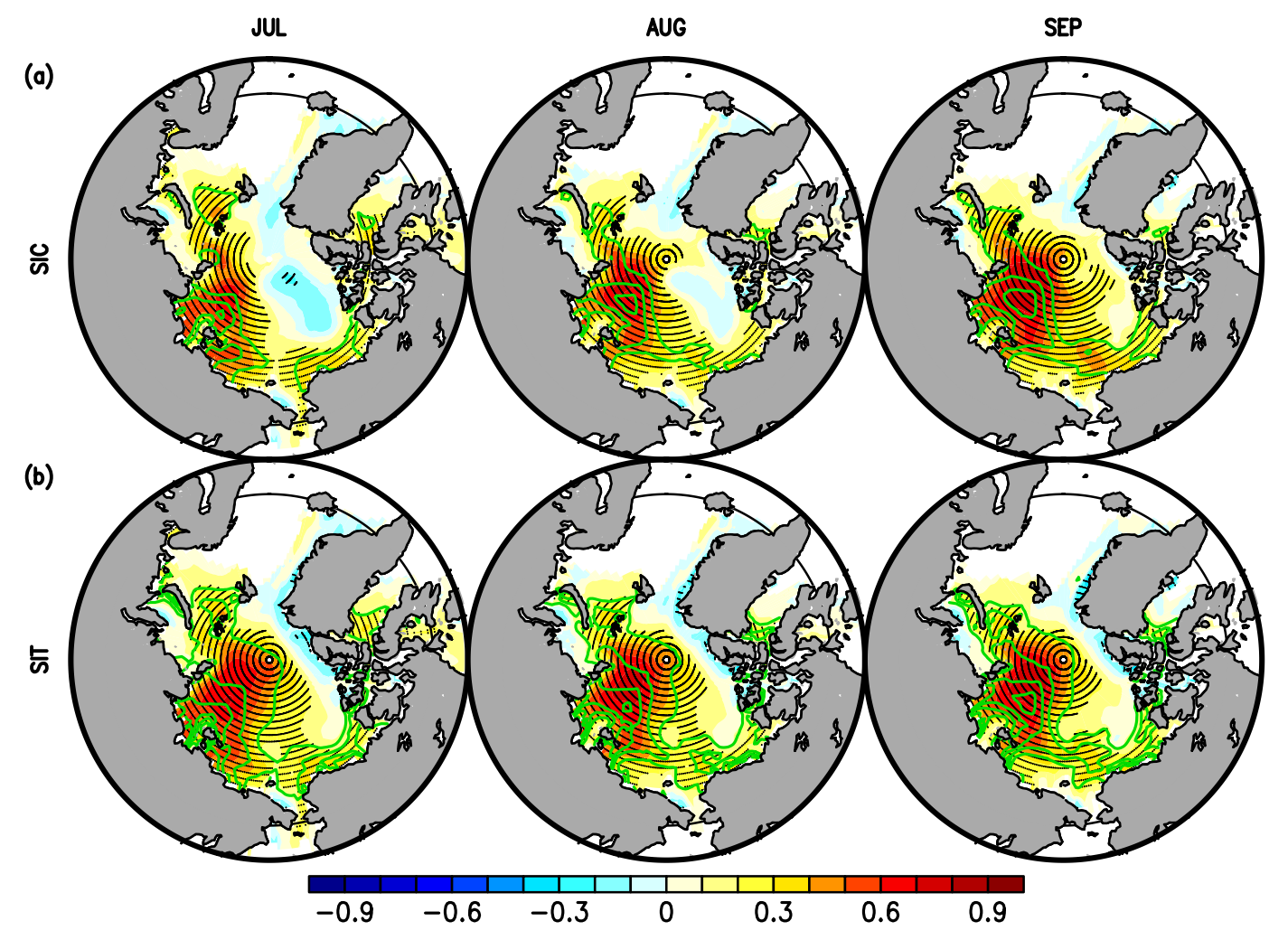

Figure S7. As in Fig. 5, except for the control experiment. 